\title{
Comparison of two forced-air warming devices for the prevention of hypothermia during abdominal surgery in the Lloyd-Davies position.
}

M. Crivits; K. Reyntjens; P. Wouters and S. De Hert

University of Ghent, Dept of Anaesthesiology, Ghent, Belgium

\section{Background}

Prevention of peri-operative hypothermia may be challenging especially in situations where positioning of the patient leaves minimal body surface area available for warming strategies.

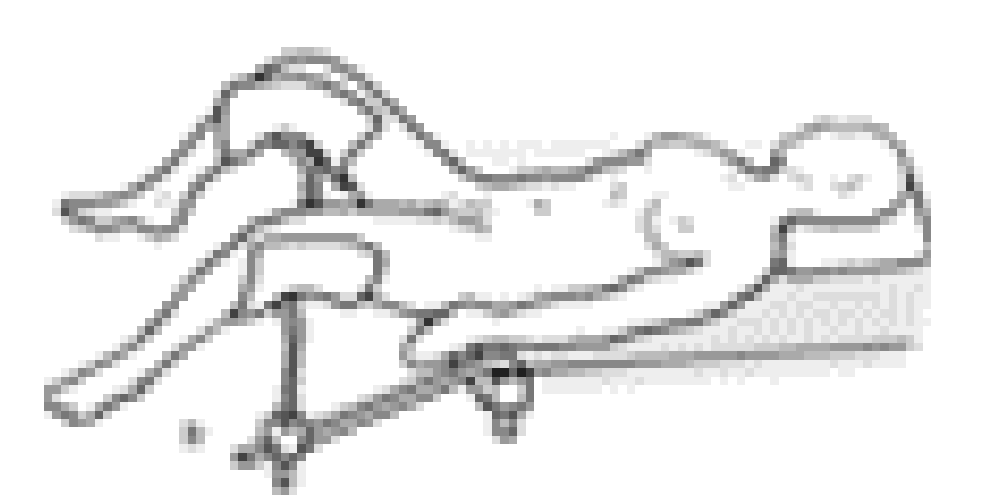

This is the case for the Lloyd-Davies position.

\section{Goal of the Study}

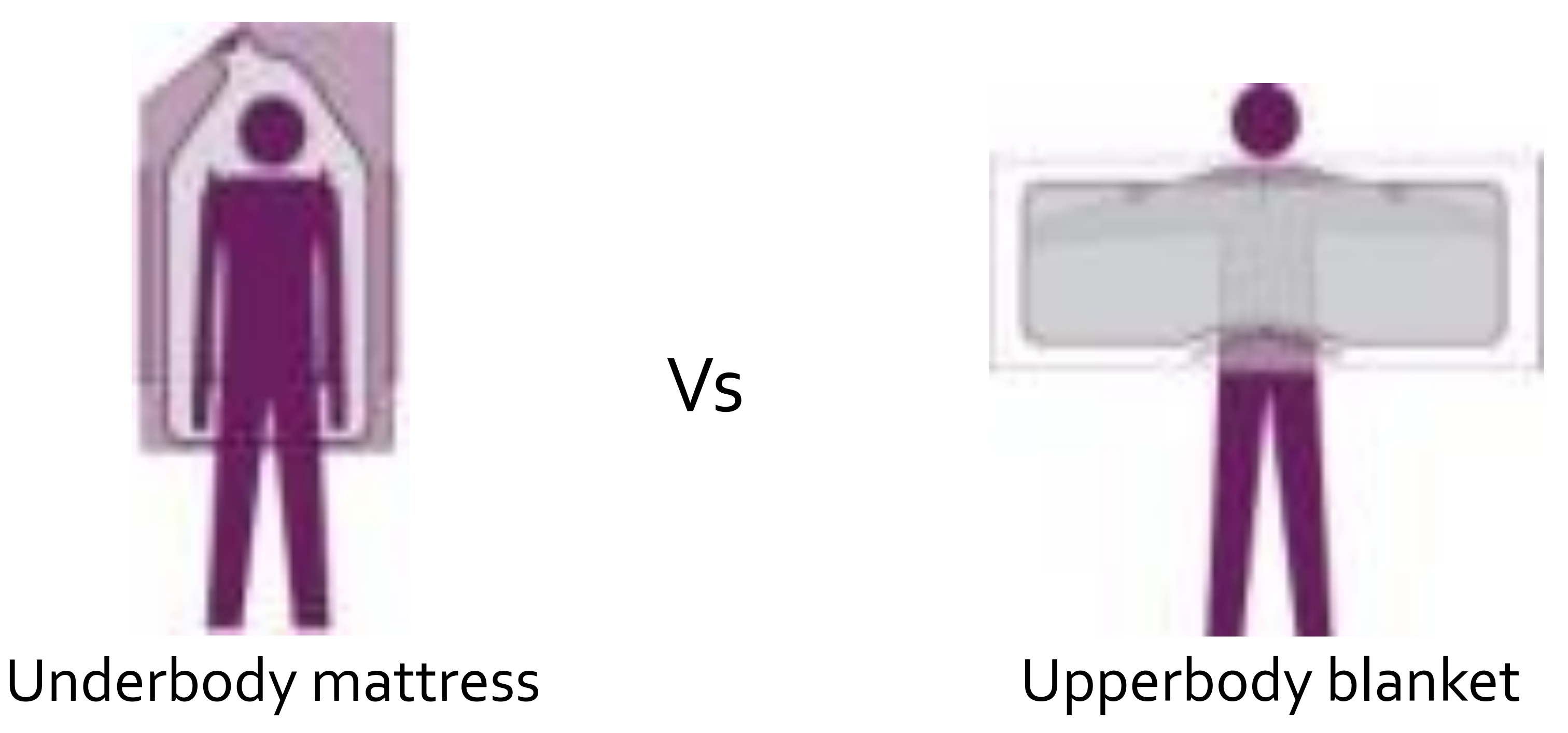

\section{Materials \& Methods}

- Forty-four patients undergoing surgery in Lloyd-Davies position

- Combined general and epidural anesthesia were randomly allocated to 2 treatment arms:

GROUP A: Underbody forced air mattress by Mistral ${ }^{\circledR}$
GROUP B: Upperbody forced air blanket by Bair Hugger ${ }^{\circledR}$

- From time of induction core temperature was monitored with an esophageal probe and recorded every 15 minutes.

- Temperatures over time in the different groups were analyzed using two-way analysis of variance for repeated measurements.

- Data are expressed as mean with standard deviation.

\section{Results}

- All patients were included in a period of 24 months.

- One patient was excluded because of malfunction of the thoracic epidural.

- Finally, data of 21 patients in group A and 23 patients in group B were used for analysis.

- There were no differences in patient characteristics between groups

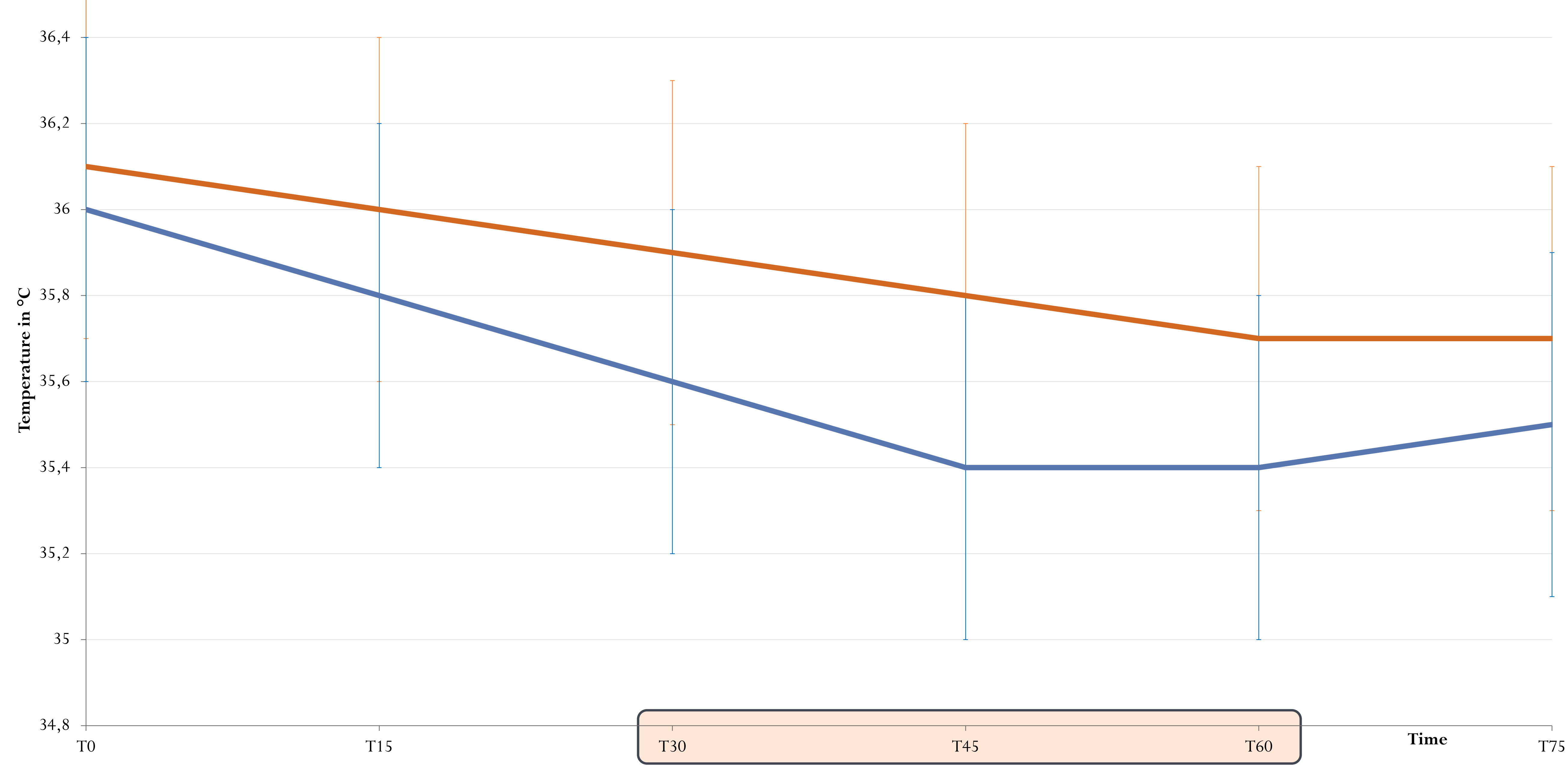

Temperatures at $\mathrm{T}_{30}, \mathrm{~T}_{45}$ and $\mathrm{T} 60$ were higher in group $\mathrm{A}$ than in group $\mathrm{B} \quad(\mathrm{P}<0.05)$

\section{Discussion}

- Early onset forced air underbody mattress may partially protect against post induction redistribution hypothermia.

- Patient installation requires some training and additional effort.

- Poor performance in obese patients and after installation of pillow for surgical exposure.

\section{Conclusion}

The forced-air warming underbody seems to provide better early temperature maintenance than the routinely used forced-air warming upperbody. 